Bangladesh J. Pl. Breed. Genet., 26(1): 11-17, 2013

\title{
MUTIVARIATE ANALYSIS IN STEM AMARANTH (Amaranthus tricolor)
}

\author{
A. U. Ahammed, M. M. Rahman and M. A. K. $\operatorname{Mian}^{1}$ \\ Department of Horticulture \\ Bangabandhu Sheikh Mujibur Rahman Agricultural University \\ Gazipur 1706, Bangladesh
}

\begin{abstract}
The genetic divergence among 22 genotypes of stem amaranth was estimated using $\mathrm{D}^{2}$ and Principal Component Analysis. The genotypes were grouped into four clusters. Cluster I, II, III and IV composed of two, four, seven and nine genotypes in succession. No relationship was found between divergence and geographic distribution of the genotypes. Maximum inter cluster distance (12.326) was observed between cluster I and III and it was minimum (3.526) between cluster I and II. The crosses between the genotypes of cluster I with that of cluster III and cluster II with cluster III would exhibit high heterosis and also likely to produce new recombinants with desired characters in stem amaranth. The yield contributing characters were leaves per plant, petiole length, stem diameter, leaf weight per plant and stem weight per plant. Leaf width, petiole length and 1000 seed weight showed maximum contribution to the total divergence. The results obtained by $\mathrm{D}^{2}$ analysis were confirmed by Principal Component Analysis.
\end{abstract}

Key words: Stem amaranth (Amaranthus tricolor); D²; PCA; cluster analysis; stem yield.

\section{INTRODUCTION}

Amaranth (Amaranthus tricolor L.) is considered to be the cheapest dark-green vegetables in tropical markets and is often described as poor man's vegetable (Shanmugavelu, 1989). Vegetable amaranth occupies a predominant position as the cheapest source of vitamins and minerals. A wide range of variability in respect of morphological trait is available in Bangladesh. But, till now, very few systematic assessment of genetic divergence has been done.

Genetic resources are, in the sense, the building blocks, fundamental not only to crop improvement program, but also for the very survival of the species in time and space (Swaminathan, 1983). Variability is essential for any plant breeding program. A new variety as per requirement of the farmers can be developed from an assembled diverse genetic stocks of any crop. So success of any breeding program depends much on the genetic variability available to the breeder and judicious selection of parents. Genetic diversity is one of the important tools to quantify genetic variability in both cross and self-pollinated crops (Griffing and Lindstrom, 1954; Murty and Aurunachalam, 1966 and Gaur et al., 1978). The quantification of genetic diversity through biometrical procedures has made it possible to choose genetically diverse parents for a successful hybridization program (Rao, 1952; Jain et al., 1975 and Rahman et al., 2005). Tomoka (1991) reported

\footnotetext{
${ }^{1}$ Department of Genetics and Plant Breeding, Bangabandhu Sheikh Mujibur Rahman Agricultural University, Gazipur 1706, Bangladesh.
} 
that evaluation of genetic diversity is important to know the source of gene for a particular trait within the available germplasm. So the breeder must have clear understanding about the nature and magnitude of variability among the collected genetic stocks. But studies pertaining to multivariate analysis of amaranth have scarcely been studied. Hence, the present study was undertaken to choose of genetically diverged parents to obtain desirable recombinant in segregating generations.

\section{MATERIALS AND METHODS}

The experiment was conducted with 22 diverse stem amaranth genotypes collected from PGRC, BARI, East West Seed Co. (Lal Teer Seed Ltd.), BRAC and different parts of the country during April to July 2007. All the genotypes were grown in a Randomized Complete Block Design (RCBD) with three replications at the experimental field, Department of Horticulture, Bangabandhu Sheikh Mujibur Rahman Agricultural University (BSMRAU), Gazipur, Bangladesh. The plot size was $1.5 \mathrm{~m}$ x 1.5 $\mathrm{m}$. The seed drilling was done between rows at $30 \mathrm{~cm}$ apart and seeds were sown continuously in the rows. Seedlings were thinned maintaining a spacing of $30 \mathrm{~cm} \times 10$ $\mathrm{cm}$ after 15 days of sowing. All the recommended package and practices were followed to raise good crop. The crop was harvested when started flowering. Data were recorded during harvesting time on plant height $(\mathrm{cm})$, leaves per plant, leaf length $(\mathrm{cm})$, leaf width $(\mathrm{cm})$, petiole length $(\mathrm{cm})$, stem diameter $(\mathrm{mm})$, primary branches per plant, leaf weight per plant $(\mathrm{g})$, stem weight per plant $(\mathrm{g})$, leaf - stem ratio, fibre $(\%)$, stem yield $(\mathrm{t} / \mathrm{ha})$ and 1000 seed weight $(\mathrm{g})$ during seed harvesting. Plot means over three replications were used to statistical analysis. Genetic diversity was studied following Mahalanobis's (1936) generalized distance $\left(\mathrm{D}^{2}\right)$ extended by Rao (1952). Clustering of genotypes was done according to Tocher's method (Rao, 1952) and Principal Component Analysis (Rao, 1964) for graphical representation of the genotypes. All the statistical analyses were carried out using GENSTAT 5.3 program in IBM computer.

\section{RESULTS AND DISCUSSION}

Analysis of variance revealed that the differences among 22 genotypes were significant for all the thirteen characters under study indicating the presence of notable genetic variability among the genotypes. The $\mathrm{D}^{2}$ values ranged from 3.526 to 12.326 and principal component scores also indicated a high degree of genetic diversity among the genotypes.

\section{Principal component Analysis (PCA)}

Thirteen (13) characters were considered for genetic diversity analysis. Eigen values of thirteen principal axes and percentage of total variation accounting for them obtained from the principal component analysis are presented in Table 1. The results revealed that the first principal axis largely accounted for the variation among the genotypes which alone contributed $39.96 \%$ of the variations followed by the $2^{\text {nd }}$ axis (18.51\%) while the first four Eigen values for the principal component axes of genotype accounted for $82.96 \%$ of the total variation among 13 characters describing 22 genotypes while the former two accounted for $58.47 \%$.

\section{Cluster analysis}

On the basis of $\mathrm{D}^{2}$ analysis, 22 genotypes of stem amaranth were grouped into four clusters (Table 2). Cluster IV contained the highest number of genotypes (nine) followed by cluster III having seven genotypes while cluster I and II having two and four 
genotypes, respectively. The clustering pattern of the genotypes under this study revealed that the genotypes collected from the same district were grouped into different clusters. The genotypes of Gazipur district were distributed in three different clusters (Table 2).

Table 1. Eigen values and percentage of variation for corresponding 13 component characters in stem amaranth genotypes

\begin{tabular}{c|ccc}
\hline \multirow{2}{*}{$\begin{array}{c}\text { Principal } \\
\text { component axis }\end{array}$} & \multirow{2}{*}{ Eigen values } & \multicolumn{2}{|c}{ Percentage } \\
\cline { 3 - 4 } & & Total variation accounted for & Cumulative \\
\hline A & 5.1954 & 39.96 & 39.96 \\
B & 2.4059 & 18.51 & 58.47 \\
C & 1.7939 & 13.80 & 72.27 \\
D & 1.3893 & 10.69 & 82.96 \\
E & 0.7394 & 5.69 & 88.65 \\
F & 0.5072 & 3.90 & 92.55 \\
G & 0.4549 & 3.50 & 96.05 \\
H & 0.2927 & 2.25 & 98.30 \\
I & 0.1354 & 1.04 & 99.34 \\
J & 0.0403 & 0.31 & 99.65 \\
K & 0.0331 & 0.25 & 99.90 \\
L & 0.0125 & 0.10 & 100.00 \\
M & 0.00 & 0.00 & 100.00 \\
\hline
\end{tabular}

Table 2. Distribution and place of collection of 22 stem amaranth genotypes in four clusters

\begin{tabular}{c|c|ccc}
\hline Cluster & $\begin{array}{c}\text { Number of } \\
\text { genotypes }\end{array}$ & Genotypes & Sources/ Place of collection \\
\hline I & 2 & SA003 & East West Seed Co. Ltd. Gazipur \\
II & 4 & SA013 & Alamgir Seed, Siddik bazaar, Dhaka \\
& & EA001 & East West Seed comp. Ltd.Gazipur \\
& & SA007 & Hamid Seed Vander, Jessore \\
& & SA014 & Samrat Seed Vander, Siddik bazaar \\
III & 7 & SA028 & Gazipur \\
& & SA018 & BARI, Gazipur \\
& & SA019 & BARI, Gazipur \\
& & SA023 & Comilla \\
& & SA033 & Plant Genetic Resource Center, BARI, Gazipur \\
& & SA037 & Plant Genetic Resource Center, BARI, Gazipur \\
IV & & SA039 & Plant Genetic Resource Center, BARI, Gazipur \\
& & SA040 & Plant Genetic Resource Center, BARI, Gazipur \\
& & SA005 & Agro Seed, Rangpur \\
& & SA006 & Bismillah Seeds, Naogaon \\
& & SA011 & Hamid Seed Store, Jessore \\
& & SA015 & Sufala Seed, BRAC \\
& & SA020 & Faridpur \\
& & SA026 & Sylhet \\
& & SA027 & Zenaidah \\
& & SA029 & Gazipur \\
& & SA035 & Plant Genetic Resource Center, BARI, Gazipur \\
\hline
\end{tabular}

Similar results also reported by Waghmode et al. (1997) in A. hypochondriacus, Pan et al. (1992) in Amaranthus tricolor, Joshi and Rana (1995) in grain amaranthus, Quamruzzaman et al. (2008) in French bean and Islam (2008) in Hyacynth bean. 
Shanmugam and Rangaswamy (1982) reported that falling of materials of same origin into different clusters was an indication of broad genetic base of the genotypes belonging to that origin.

The maximum inter cluster distance was observed between cluster I and III (12.326) followed by cluster II and III (9.082) (Table 3). Intermediate or moderate inter cluster distance was observed between I and IV (7.661) followed by cluster III and IV (5.852) and II and IV (5.485). The minimum inter cluster distance was observed between cluster I and II (3.526) indicating that the genotypes of these clusters were genetically closed or more homogenous. The intra-cluster distance varied from 0.639 to 1.115 comprising two and four genotypes, respectively.

Kanthaswamy (2006), reported that 74 amaranth genotypes of were grouped into 12 clusters, Oboh (2007) observed four clusters for 16 amaranth (A. hybridus), Shukla et al. (2010) obtained six clusters for 39 amaranth strains and Akhter et al. (2013) discriminated 17 amaranth genotypes into four clusters.

Table 3. Intra (bold) and inter cluster distances $\left(D^{2}\right)$ of 22 stem amaranth genotypes of stem amaranth

\begin{tabular}{c|c|c|c|c}
\hline Cluster & I & II & III & IV \\
\hline I & $\mathbf{0 . 6 3 9}$ & & & \\
II & 3.526 & $\mathbf{1 . 1 1 5}$ & & \\
III & 12.326 & 9.082 & $\mathbf{1 . 0 6 9}$ & \\
IV & 7.661 & 5.485 & 5.852 & $\mathbf{1 . 0 3 2}$ \\
\hline
\end{tabular}

The mean values of cluster I ranked first for fibre (\%), leaf-stem ratio and 1000 seed weight and second for primary branches per plant and leaf length (Table 4). Where as minimum mean values for leaf width, petiole length, stem diameter, leaf weight, stem weight and stem yield was observed. Cluster II comprising four genotypes had the highest cluster mean for primary branches per plant and second for leaf width, petiole length, leaf-stem ratio and fibre (\%), while the minimum mean values for plant height, leaves per plant, leaf length and 1000 seed weight was observed.

Table 4. Cluster mean values for different characters of stem amaranth genotypes

\begin{tabular}{l|c|c|c|c}
\hline \multirow{2}{*}{\multicolumn{1}{c}{ Characters }} & \multicolumn{4}{c}{ Cluster } \\
\cline { 2 - 5 } & I & II & III & IV \\
\hline Plant height (cm) & 120.00 & 119.56 & 128.62 & 131.75 \\
Leaves per plant & 16.10 & 14.75 & 21.29 & 19.48 \\
Leaf length (cm) & 20.28 & 19.44 & 20.10 & 20.46 \\
Leaf width (cm) & 9.67 & 10.99 & 11.19 & 10.78 \\
Petiole length (cm) & 10.05 & 10.97 & 11.54 & 10.66 \\
Stem diameter (mm) & 18.16 & 19.15 & 22.62 & 20.94 \\
Primary branches per plant & 2.39 & 2.50 & 1.65 & 2.26 \\
Leaf weight per plant (g) & 66.33 & 73.81 & 109.79 & 92.10 \\
Stem weight per plant (g) & 172.26 & 243.98 & 389.91 & 303.70 \\
Leaf :Stem ratio & 0.39 & 0.30 & 0.28 & 0.30 \\
Fibre (\%) & 0.99 & 0.95 & 0.88 & 0.87 \\
1000 seed weight (g) & 0.78 & 0.73 & 0.76 & 0.75 \\
Stem yield (t/ha) & 57.36 & 81.24 & 129.84 & 101.13 \\
\hline
\end{tabular}


Cluster III comprising seven genotypes had the highest cluster mean for leaves per plant, leaf width, petiole length, stem diameter, leaf weight per plant, stem weight per plant and stem yield (t/ha) and second for plant height and 1000 seed weight, where as minimum mean values for primary branches per plant and leaf-stem ratio was observed. These results indicated this cluster possessed such characters which were responsible for higher yield. So that for higher yield selection of superior genotypes can safely be done in this cluster. Cluster IV comprising nine genotypes had the highest cluster mean for plant height and leaf length and second for leaves per plant, stem diameter, leaf weight per plant, stem weight per plant, leaf-stem ratio and stem yield (t/ha). Where as the minimum mean value for fibre $(\%)$ was observed in this cluster.

Considering yield performance, cluster distance and cluster mean the genotypes SA003 and SA013 from cluster I, the genotypes SA014 and SA028 from cluster II, genotypes SA023, SA033, SA037, SA039 and SA040 from cluster III and genotypes SA005, SA006 and SA029 from cluster IV may be considered better parents for future hybridization program.

Based on principal component axes I and II, a two dimensional scattered plotting diagram $\left(Z_{1}\right.$ and $\left.Z_{2}\right)$ of the genotypes are presented in Figure 1, reflecting the position of the genotypes. The scattered diagram revealed apparently showed four clusters. Distantly located genotypes of different clusters were SA003 and SA013for cluster I and SA018, SA019, SA023, SA033, SA037, SA039 and SA040 for cluster III. Pattern of distribution of genotypes in the scattered diagram revealed that considerable variability exist among the genotypes.

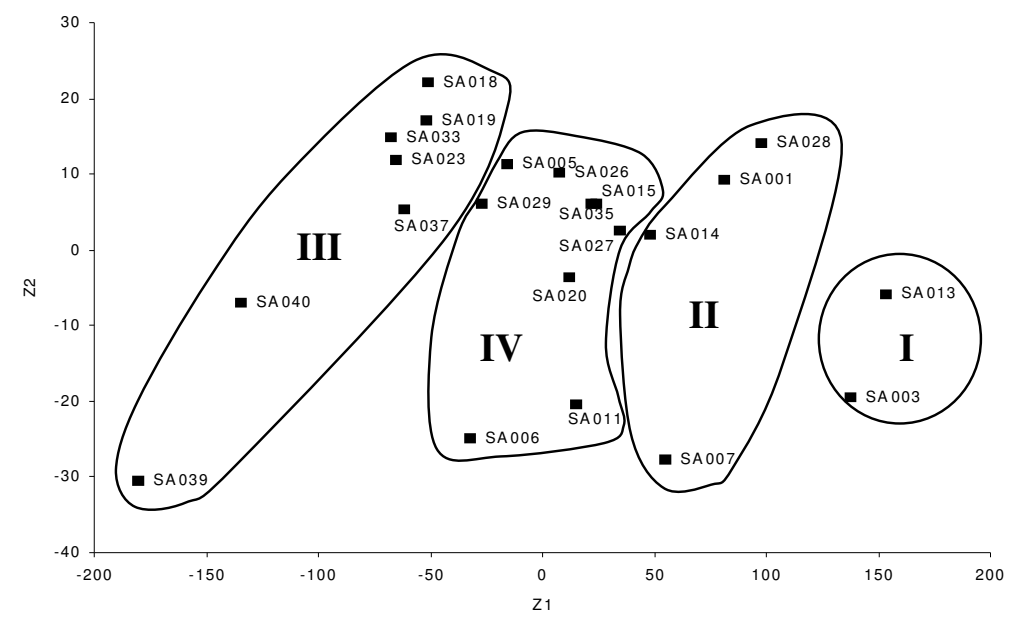

Fig 1. Scatter distribution of 22 genotypes based on their principal component scores super imposed with clustering

\section{Contribution of the characters towards divergence of the genotypes}

The results of PCA revealed that in vector I $\left(Z_{1}\right)$ the important characters responsible to genetic divergence in the major axis of differentiation were leaves/plant (0.110), primary branches per plant (0.307), and leaf weight per plant (0.117) having positive vector values (Table 5). While in vector II $\left(\mathrm{Z}_{2}\right)$ which was second axis of differentiation, stem weight per plant (0.022), leaf-stem ratio (15.428), fiber (8.247\%) and stem yield (t/ha) (0.066) having positive vector values played a major role while rest of the characters played a minor role in the second axis of differentiation. The role of 
leaf width, petiole length, and 1000 seed weight in both the vectors indicated the important component of genetic divergence among the 22 genotypes of stem amaranth.

\section{$D^{2}$ and PCA}

The clustering pattern of $\mathrm{D}^{2}$ analysis in Table 2, has followed the same trend of distribution of the genotypes in PCA (Fig 1). $\mathrm{D}^{2}$ and PCA were found to be an alternative method in giving the information regarding the clustering pattern. Moreover, the PCA provides information on contribution of the characters towards divergence.

Table 5. Latent vectors for 13 principal component characters of stem amaranth genotypes

\begin{tabular}{lcc}
\hline Characters & Vector-I & Vector-II \\
\hline Plant height $(\mathrm{cm})$ & -0.051 & -0.172 \\
Leaves per plant & 0.110 & -0.255 \\
Leaf length (cm) & -0.138 & -0.619 \\
Leaf width $(\mathrm{cm})$ & 0.145 & 0.458 \\
Petiole length $(\mathrm{cm})$ & 0.478 & 0.612 \\
Stem diameter (mm) & -0.243 & -1.088 \\
Primary branches per plant & 0.307 & -0.201 \\
Leaf weight per plant (g) & 0.117 & -0.008 \\
Stem weight per plant (g) & -0.046 & 0.022 \\
Leaf: stem ratio & -25.840 & 15.428 \\
Fibre (\%) & -3.093 & 8.247 \\
1000 seed weight (g) & 2.311 & 20.495 \\
Stem yield (t/ha) & -0.139 & 0.066 \\
\hline
\end{tabular}

The crosses involving parents belonging to the maximum divergent clusters were expected to manifest maximum heterosis and also wide variability in genetic architecture. Ramnujam et al. (1974) in mungbean and Mian and Bhal (1984) in chickpea reported that parental clusters separated by medium $\mathrm{D}^{2}$ values exhibited significant and positive heterosis for seed yield and some of its components in mungbean. Thus crosses between the genotypes of cluster I with that of cluster III and cluster II with cluster III would exhibit high heterosis and also likely to produce new recombinants with desired characters in stem amaranth.

\section{REFERENCES}

Akther, C. A., M. Hassan, M. S. Raihan, M. M. Hossain and M. A. K. Mian. 2013. Genetic divergence in stem amaranth (Amaranthus tricolor L.) genotypes for yield and its component characters. The Agriculturist. 11(1): 82-88.

Oboh, B. 2007. Multivariate analysis of the diversity among some Nigerian accessions of Amaranthus hybridus. International Journal of Plant Breeding and Genetics 1: 89-94.

Gaur, P. C., P. K. Gupta and H. Kishore. 1978. Studies on genetic divergence in potato. Euphytica. 27: 361-368.

Griffing B. and Lindstrom E. W. 1954. A study of combining abilities of corn inbreds having varying proportions of corn belt and non- corn belt germplasm. Agronomy Journal. 46: 545-552.

Islam, M. S. 2008. Genetic diversity, combining ability and heterosis in Hyacinth bean (Lablab purporeus (L). Sweet]. Ph.D. Dissertation, Department of Horticulture, BSMRAU, Gazipur, Bangladesh. pp.66, 67, 75, 144 and 155. 
Jain, S. K., C. Qualest, G. M. Bhatt and K. K. Wu. 1975. Geographical patterns of phenotypic diversity in a world collection of wheat. Crop Science. 15: 700-704.

Joshi, B. D. and J. C. Rana. 1995. Genetic divergence in grain amaranth (Amaranthus hypochondriacus). Indian Journal of Agricultural Sciences. 65(8): 605-607.

Kanthaswamy, V. 2006. Studies on multivariate analysis in amarantus. International Journal of Agricultural Science. 2(2): 317-319.

Mahalanobis, P. C. 1936. On the generalized distance in statistics. Proc. Natl. Int. Sci., India. 2: 49-55.

Mian, M. A. K. and P. N. Bhal. 1989. Genetic divergence and hybrid performance in Chick pea. Indian Journal of Genetics. 49(1): 119-129.

Murty, B. R. and V. Arunachalam. 1966. The nature of genetic divergence in relation to breeding system in crop plants. Indian Journal of Genetics. 26A: 188-198

Pan, R. S., P. S. Sirohi and N. Sivakami. 1992. Genetic divergence in vegetable amaranth. Indian Journal of Horticulture 49(2): 183-186.

Quamruzzaman, A. K. M., M. H. Rahman, A. N. M. Mamun, S. M. L. Rahman and M. N. Islam. 2008. Multivariate analysis in French bean (Phaseolus vulgaris L.). Bangladesh Journal of Progressive Science and Technology. 6(2): 491-494.

Rahman, M. M., A. K. M. A. Islam and S.I. Hossain. 2005. Genetic variability, correlation and path analysis in amaranth (Amaranthus tricolor L.). Bangladesh Journal of Life Science. 17(1): 129-134.

Ramnujam, S., A. S. Tiwawary and M. R. Mehra. 1974. Genetic divergence and hybrid performance in mungbean. Theoretical and Applied Genetics. 44(5): 211-214.

Rao, C. R. 1952. Advanced statistical Methods in Biometrical Research. John wiley and Sons, New York. pp.51-74.

Rao, C. R. 1964. The use and interception of principal component analysis in applied research. Sankhya. 22: 317-318.

Shanmugam, A. S. and Rangasamy S. R. S. 1982. Genetic diversity for quantitative characters in green gram. Madras Agriculture Journal. 69(10): 631-637.

Shanmugavelu, K. G. 1989. Amaranths. In: Production Technology of vegetable crops. Oxford and IBH publishing Co. Pvt. Ltd. New Delhi. pp. 680-699.

Shukla, S., A. Bhargava, A. Chatterjee, A. C. Pandey and B. K. Mishra. 2010. Diversity in phenotypic and nutritional traits in vegetable amaranth (Amaranthus tricolor L.), a nutritionally underutilized crop. Journal of Science, Food and Agriculture. 90(1): 139-144.

Swaminathan, M. S. 1983. Genetic conservation: microb to man presidential Address xv. International Congress of Genetics, New Delhi, p. 31.

Tomoka, N. 1991. Genetic diversity and land race differentiation of mungbean (Vigna radiate (1) wilczek) and evaluation of its wild relatives (The sub-genus cerato tropics) as breeding materials. Tech. Bull. Trop. Res. Centre, Japan, No. 28. Ministry of Agric. Forestry and Fisheries, Japan, p. 1.

Waghmode, B. D., S. C. Patil, A. S. Jadhav, S. V. Pawar and A. N. Pawar. 1997. Genetic diversity in amaranthus (Amaranthus hypochondriacus L.). Crop Improvement. 24(1): 105-108. 